\title{
EKOMUSEUM BERGSLAGEN - FRÅN IDÉ TILL VERKLIGHET
}

\author{
Örjan Hamrin
}

Om man läser om Ekomuseum Bergslagens tillkomst, finner man ofta olika versioner av hur museet byggdes upp genom inspiration av ekomuseer i Frankrike. Men egentligen är detta bara en del av sanningen. I forrta hand masste man betrakta det som en $i$ huvudsak svensk skapelse, där de franska idéerna $i$ ett skede gav den extra kraft och inspiration som behövdes.

Ekomuseum Bergslagen mötte i portgången härd kritik från flera svenska museimän just för att man "okritiskt anammat begreppet ekomuseum utan att fullt och fast utgå frän de franska forrebilderna". Jag tror inte att det skulle ha varit lyckosamt om man hundraprocentigt tillämpat de franska grundidéerna.

Ett ekomuseum i Sverige var en utmaning i sig, men kunde aldrig bli lika utmanande som vad Le Creusot blev i Frankrike vid mitten av 70-talet. Ekomuseum Bergslagen byggde vid öppnandet år 1986 till stor del på i svensk museisyn redan existerande strukturer, synen på frivilliga krafter, på hembygdsrörelsen och vår välorganiserade folkbildning. Man bör även nämna intresset för industrialismen inom den svenska kulturminnesvården. Där fransmännen tvingades in på delvis nya områden, kunde Ekomuseum Bergslagen i stället ta redan uppbyggda verksamheter i sin tjänst.

Därmed vill jag inte på något sätt förringa betydelsen av tillkomsten av Ekomuseum Bergslagen. Det arbetar på ett sätt som fătt förvånansvärt få efterföljare i Sverige med tanke på de resultat som upp- nåtts. Museet är fortfarande unikt i landet - unikt i sitt sätt att ta till vara svenska förutsättningar och väcka liv och kraft i ett landskap med hjälp av franska idéer. Kanske kan man säga att det i stället blivit i Danmark som Ekomuseum Bergslagen fătt sina tydligaste efterföljare. På så vis skulle man kunna tala om en ny 'skandinavisk' typ av ekomuseum.

Med dessa påpekanden vill jag påstå att Ekomuseum Bergslagen inte är ett franskt ekomuseum. Men hur kom museitankarna till? Hur formades idéerna till verklighet? Det bör påpekas att de trakter ekomuseet omfattar ingalunda är valda av någon slump. Området hade särskilda förutsättningar genom sin förhistoria som spelat stor roll och gör det än i dag. 
ÖRJAN HAMRIN

1920-30-TAL - KARL-ERIK

FORSSLUND - PIONJÄREN

På Storgården vid sjön Väsmans strand nära Ludvika bodde Karl-Erik Forsslund, författare, hembygdsvårdare och folkbildare. Här formulerade han sina idéer om hembygden i sann rousseauansk anda idéer som blev grundläggande för den svenska hembygdsrörelsen. Här byggde han upp folkets egen folkhögskola Brunnsvik. Här kämpade han för att den gamla bergsmanskulturen skulle bevaras i gruvor, hyttor och bergsmansgårdar.

Redan på 1920-talet lyckades han för Ludvika Hembygdsforrening förhandla till sig den s.k. Öbergska bergsmansgården och göra den till hembygdsgård och museum med alla byggnader på ursprunglig plats. Hans intresse riktade sig sedan mot den då just nedlagda bergsmanshyttan Flatenberg nära Smedjebacken. Han klassificerade den som museum och lät registrera alla föremål som fanns kvar i bergsmansbyn. Han fick bedriva en kamp i rikspressen för att stoppa en planerad rivning av hyttan. "Man river inte ett museum", skrev Karl-Erik Forsslund.

Svårare fick han att bevara en lämplig gruvmiljö. I stället lät han samla gruvbyggnader och maskiner till ägorna vid den Öbergska gården som ett gruvtekniskt friluftsmuseum. När Ludvika Gruvmuseum öppnade sina portar år 1938 var det det första friluftsmuseet $\mathrm{i}$ världen för industrihistoria.

Om man skulle se dessa tre enheter $\mathrm{i}$ ett helhetsperspektiv, kan man säga att KarlErik Forsslund ville bygga ett «museilandskap» - där frivilliga intresserade personer skulle arbeta med sin historia. Detta var pionjärinsatser, ett museologiskt nytän-

\section{Karl-Erik Forss lunl: Rälda Ivarlevorna av våa hruksklultiur! Aftanbladet $3 y / 5: 30$}

Ett friluftsmuseum i Dalarna som redan råkat i förfall.

Hög tid att gripa in - oersättliga förluster hota

Frän skiriftstatharoin $K A R L$. BRIK FORSSLUND har Afion: bladel moltagit nedanstando iniressacäcklands bidrag till don $i$ Aftanbladsts spalter opprode diskussionen rörand̄o víra Kullurhistoriska byggnadsminnen i privat ajo, till vilkens framtida wâr Nordislia muscets stiyresman, profescor Andreas Lindblom, i sitt lal

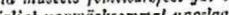
Livligt instimmer jag i och bolt Glrive: jag under det inlizs av B. C. oob det utlalando av profetsót dndreas Lindblom, som lästes i Aftenbladots öndagenumger rörando várden as kulturhistorisła byggnademinnon $\mathrm{i}$ enskild

Yigo. ha en lagetistning angiaude fridfsentug ar natiormimim, nien vi vänta alltjŭmt pà möjligheten att pá liknarido ealt kunna fa sullurminneu lagligen sksddado och rirdado. En asdan mojlighet blir nu for war dag att alltmer trängando behov, dầ vâtrs stös: гa ammïllen - och efter doros mas el.

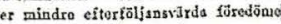

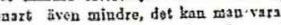
Givertygad oun - jis grund av dén mo. derna trafiken hota als onabit och ra ditals torindra gestalt - aft fà sio egen gamla pruzel nästan helt ulpta. nad och klälas om $i$ on alldeles ny oet.

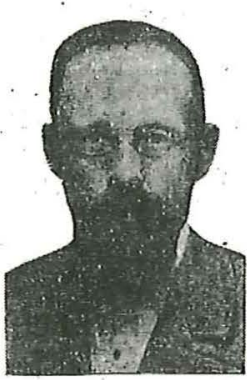

Bi ERIK FORSSLUND.

och from eltt omraxde en motsvaright till negotlulteuren jnom musil: oct dans (man kan bir not talu on ej biot) en toteraxighot, utan även ett samaband - och minnas uttrycket om arkitokturen eásom forstonad oller frusen musilit)

Dot ir ippenbast, ate här just nut

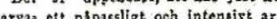
hote att ej blotf iudda rad som finn hivar ar os lingt mojilist tallla dot rid lif ciom propaplie upprostning oub emeirdnat is traditionell grund

Karl-Erik Forsslund pläderar for brukens kulturminner i Aftonbladet 1930.

kande och något av ett embryo för Ekomuseum Bergslagen.

\section{FÖREGANGSINSATSER I VÄSTMANLAND}

Det finns fler «ekomuseala» föregångare inom området. Vi kan nämna generalkon- 
sul Axelsson-Johnson vid Avesta-koncernen. Han kände starkt för det gamla bruket vid Ängelsberg och kom att genomföra en stor praktisk bevarandeinsats. Medan liknande anläggningar gick i graven runt omkring i Bergslagen, underhölls byggnader och ugnar, hammare och vattenhjul. I dag finns Ängelsberg med på Unescos World Heritage List.

\section{DALARNAS MUSEUM

I LÄNET - HUSBYRINGEN

År 1967 kom Erik Hofrén till Dalarna som ny landsantikvarie. Han insåg värdet av Karl-Erik Forsslunds tankar och ansåg att ett väl fungerande länsmuseum måste bedriva en stor del av sin verksamhet $\mathrm{i}$ landskapet i samverkan med kommuner och hembygdsrörelse.

Vid denna tid hade Olof Sundell vid Korsnäs $\mathrm{AB}$ tagit upp tankarna på att restaurera ödebruket vid Silvhytteå nära Hedemora. Kontakten med Erik Hofrén innebar ett fruktbart samarbete som skulle leda till att en sex mil lång kultur- och naturled, Husbyringen, öppnades år 1970 . Leden organiserades som en museistiftelse, vilken fungerade som en paraplyorganisation för flera mindre museer. Husbyringen kom att bli en föregångare för ekomuseer av den skandinaviska modellen. $\mathrm{Nu}$ har Husbyringen fyllt 25 år och kallar sig "Sveriges första ekomuseum».

\section{4 - JOHAN AHLBÄCKS ATELJÉ}

En viktig händelse för tillkomsten av ekomuseet var när författaren, då nyanställd på Dalarnas museum, och Erik Hofrén inbjöds till den nyligen avlidne konstnären Johan Ahlbäcks ateljé i Smedjebacken.
I denna anspråkslösa vindskupa fick vi se 29 en samling av bilder som alla visade det tunga slitsamma industriarbetet i Bergslagen. Där låg de - hundratals bilder med intensiva arbetslivsskildringar. Samlingen gjorde ett mycket starkt intryck på oss.

En upplevelse av detta slag kan ge upphov till andra idéer och framkomliga vägar inom andra områden. Det blev så småningom en bok, Arbetets målare, om Ahlbäcks liv och konst, som dessutom filmades. Med bok, film och konstsamling i grunden inledde vi ett mycket fruktbart samarbete med Riksutställningar. Det resulterade $\mathrm{i}$ en vandringsutställning som gick land och rike runt. Det viktigaste var kanske att Ahlbäcks konst öppnade dörrar som tidigare varit stängda.

\section{DET DECENTRALISERADE MUSEET}

Vid den här tiden, åren 1978-1980, hade Erik Hofrén arbetat vidare med museistrukturen i Dalarnas 15 kommuner. Den grundidé som utvecklades innebar att varje kommun skulle satsa på en egen museiverksamhet, som samtidigt skulle ingå som en del av länsmuseiverksamheten. Dalarnas museum skulle bli ett nav och tillsammans med kommunerna skulle museihjulet bringas att snurra.

Det fanns inom systemet redan tre museer - Geologiska museet i Borlänge, Siljansfors Skogsmuseum i Mora och kultur- och naturleden Husbyringen i Hedemora kommun.

Planerna riktades mot Västerbergslagen. Den intensiva och lyckosamma satsningen på Johan Ahlbäcks konst hade givit nya kontakter, nya möjligheter. Kunde lämningarna av den industri Ahlbäck målat av bli föremål för en ny typ av museisatsning? 
30 Jag presenterade för Erik ett utkast till en «museiväg» inom Ludvika kommun. Mitt förslag var att Husbyringen här skulle få en "syster" med hörnstenar i Ludvika Gruvmuseum, i Grangärde by samt i Grängesbergs gruvor. Denna «Bergslagstriangel» skulle innesluta sjön Väsman. Erik var positiv, men han tyckte samtidigt att denna led inte var lika tydlig som Husbyringen varit inom Hedemora kommun. Var fanns den så intressanta Finnmarken? Inte kunde den glömmas bort.

Men så kom nästa utkast till "Bergslagstriangeln» där jag helt enkelt utökat den med Grangärde Finnmark. Även denna gång möttes jag av en viss tveksamhet från Hofréns sida. Vägen blev för lång och för otydlig, och var fanns Johan Ahlbäck? Han är ju i Smedjebacken, sa jag, den kommunen får vi ta sen. - Måste man absolut ta hänsyn till kommungränserna? Kan vi inte göra en skiss på ett gemensamt museiprojektet för båda kommunerna? Då kan det arbete vi lagt ned på att presentera Ahlbäck användas som en resurs för hela Västerbergslagen!

Jag kände att Husbyringen-idén, som jag var en stor tillskyndare av, inte längre hade relevans. Men vad skulle kunna komma i stället? Eva Perssons artikel i tidskriften Form, Allas museum, som handlade om Le Creusot blev en förlösande läsning. De förutsättningar vi redan hade, kunde med stor fördel kombineras med de franska idéerna.

\section{EKOMUSEIPLANERNA TAR FART UNDER 1980-TALET}

Det blev nu dags att på allvar utveckla museiplanerna. Vi hade under våren gjort en sammanställning som vi presenterade för kommunerna Ludvika och Smedjebacken. Detta ledde till att vi fick uppmaning att arbeta vidare. Till att börja med fick vi klartecken på att bygga en utställning i Smedjebacken kring Johan Ahlbäcks konst - den finns kvar än i dag. När utställningen öppnades, blev den samtidigt en bekräftelse från Smedjebackens kommun att man accepterade idéerna om ett ekomuseum tillsammans med Ludvika.

Men det som på allvar skulle sätta igång ekomuseiarbetet var att de båda hyttorna i Flatenberg i Smedjebacken och Klenshyttan i Ludvika kommun skulle restaureras genom riksantikvarieämbetets försorg. Intressant är att konstatera att just vid Flatenberg, där Karl-Erik Forsslund en gång kämpat för nya museitankar, skulle restaureringen ge de gamla idéerna näring.

Vid denna tid - våren 1983 - bjöd Erik Hofrén in landsantikvarierna och länsantikvarierna i Västerås och Örebro till en överläggning i Falun. Idéerna till «Ekomuseum Västerbergslagen» presenterades. Vi fick en omedelbar respons från kollegorna i Västerås. De avsåg att diskutera ett eget museiprojekt som skulle kunna nära anslutas till vårt eget. Från Örebros sida föredrog man att ligga lågt.

Den grundläggande inventeringen gjordes av Hans Rehnberg vid riksantikvarieämbetet. Den utgick från en tematisk grundstruktur med gruvan - hyttan - bruket energi - transporter - bergsmansgården finnmarken. Vi var oense om hur man skulle betrakta konstnärer, författare och andra kulturpersonligheter. Dessa såg Rehnberg ingen direkt grund för att ha med, då han var ganska strikt byggnadsinriktad. Men det skulle ha varit fel att inte $\mathrm{i}$ den färdiga strukturen foga in konstnärer och författare som Johan Ahlbäck, Karl-Erik Forsslund 


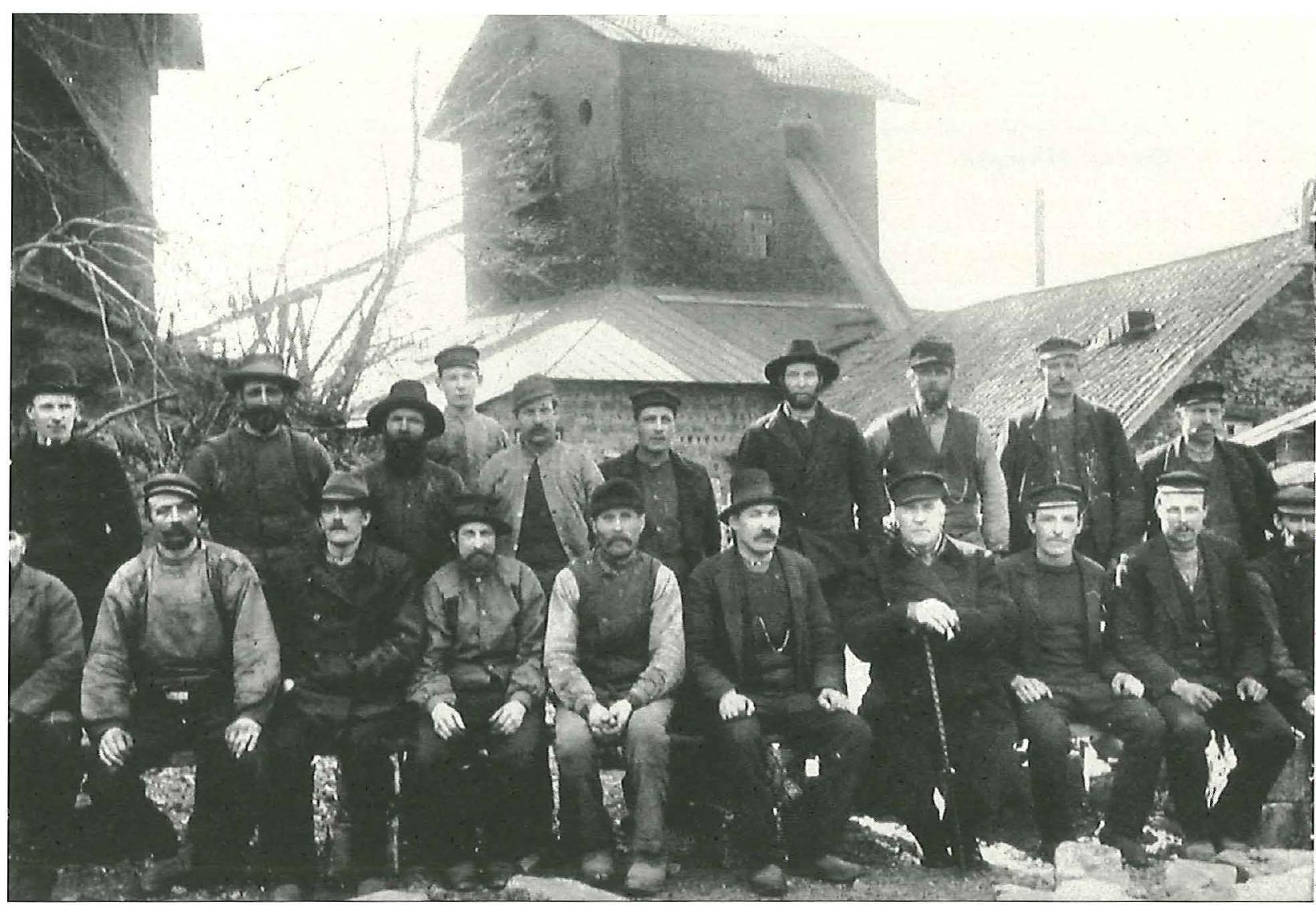

Arbetslaget vid Flatenbergs hytta år 1912. Foto: Dalarnas museum.

eller den högt uppskattade poeten Dan Andersson från finnmarken. Vi lade därför till ett tema med kulturpersonligheter. $\mathrm{Nu}$ återstod att presentera idéerna i bokform.

Under våren 1984 var de två publikationerna klara. Ekomuseum Västerbergslagen för Ludvika och Smedjebacken och Ekomuseum Bergslagen i Västmanlands län för Norberg, Fagersta Skinnskatteberg, Hallstahammar och Surahammar.

Vid bearbetningen av materialet kan man säga att själva utformningen av ett «skandinaviskt ekomuseum» kom på pränt. Det skiljer sig - som framgått från de franska ursprungsidéerna. Här bör påpekas några ytterligare skillnader. «Vårt» ekomuseum hade aldrig avsikten att äga objekten i museet, utan snarare vara en paraplyorganisation. En annan skillnad är att redan då samarbetet med den turistiska organisationen inom kommunerna betonades. Den ursprungliga franska formen var strikt inriktad mot områdets invånare
- i mycket liten grad mot turister.

Viktigt var att det - för åtminstone Västerbergslagens del - rörde sig om ett museum inom ramen för «det decentraliserade länsmuseet». Därför skulle verksamheten knytas till kulturförvaltningarna. Samtidigt skulle museet samarbeta med hembygdsrörelsen och ge frivilliga krafter stort inflytande. Behovet av att bygga upp en lokal identitet i området påtalades. Men en sak hade vi inte löst; Hur skulle ekomuseet drivas? Frågan lämnades öppen.

Nu skulle nästa etapp inledas. Men hur skulle vi gå vidare? Klart var att vi måste 1) förankra idéerna i kommunerna, 2) finna de slutliga objekten, 3) finna en organisationsform, 4) finna en finansieringsform.

$\mathrm{Nu}$ följde en fas, där de båda länsstyrelserna tog initiativen. De fick fram medel för två utredare som skulle finnas i området och arbeta vidare med de fyra frågorna. 
UTREDNINGEN KLAR OCH EKOMUSEET ÖPPNAR

Utredningen om det färdiga ekomuseet lades fram 1985 - men ändå åt sidan. Det berodde delvis på att det som föreslogs var ett alltför dyrt och till synes alltför centraliserat museum, som skilde sig från de ursprungliga idéerna. Men det viktigaste utredarna åstadkommit var, att de tagit upp diskussionen direkt med alla sju kommunernas ledningar och att de förordade ett samgående mellan de planerade två ekomuseerna.

Hur skulle man gå vidare? Här togs ett radikalt grepp. Man bestämde att det bästa sättet att se hur ekomuseet borde fungera, var att sätta igång verksamheten för att den under tre försöksår skulle finna sin egen form - utan ytterligare utredning. Beslut fattades om att öppna museiprojekten under det samlade arbetsnamnet Ekomuseum Bergslagen lördagen den 31 maj 1986. Fyra personer anställdes. Kvartetten hade i stort sett sex månader på sig att ta fram guidebok, skyltar till och på objekten och foldrar. Ledningsgruppen kom i praktiken också att arbeta med ekomuseet liksom tjänstemän i alla de sju kommunerna; dessutom tillkom de frivilliga intressenterna vid objekten. Nu verkade det plötsligt hända mycket överallt.

Så kom den stora dagen. Solen sken från en klarblå himmel. I Karmansbo skedde huvudinvigningen genom riksantikvarien Roland Pålsson. I stället för att klippa band knöt Folke Wretman från Skinnskatteberg i Västmanland ihop ett band med kommunalrådet Bertil Andersson från Smedjebacken i Dalarna, för att visa att man nu gått över länsgränsen. Stig Adolfsson satte fart på vattenhjulet.
Guideboken Järn bryter bygd såldes. Ekomuseet var igång.

\section{EKOMUSEET UTVECKLAS}

Vi hade fått kritik för att ekomuseet var ett hastverk och vi arbetade vidare på skyltning, på en marknadsundersökning och på kursverksamhet. Inom det senare området etablerades ett mycket gott samarbete med folkhögskolan i Skinnskatteberg, vilket ännu består.

Hittills hade vi arbetat utifrån de båda residensstäderna. Våra kontor hade varit $\mathrm{i}$ länsmuseerna eller länsstyrelserna. Från och med 1990 satsade vi på att bygga upp ett första kontor inom området och ekomuseet fick sitt första egna telefonnummer.

$\mathrm{Nu}$ gällde det att se över hur verksamheten skulle etableras för att fà en fortsättning efter projekttiden. Här togs slutgiltig ställning till organisationsform och om eventuell delning av ekomuseet mellan länen. Efter en ganska hård debatt bestämdes att man skulle fortsätta tillsammans under gemensam ledning.

Exakt tre år efter öppnandet blev ekomuseet 1990 permanentat i stiftelseform, där de båda länsdelarna tillmättes lika stor betydelse. Verksamheten hade kommit för att stanna. Detta år arbetade man med seminarier för att intensivare finna samarbetsformerna med dem som arbetade frivilligt - numera organiserade i Ekorådet.

Ar 1988, i slutet av oktober, medan Ekomuseum Bergslagen ännu var på projektstadiet, reste jag runt med Kenneth Hudson som för juryn för EMYA - det årliga europeiska museipriset - bedömde projektet. Trots att det var efter säsongen och ruggigt och kallt, fick han en positiv uppfattning om ekomuseet. 
Ett år senare inbjöds ekomuseet till EMYA:s prisutdelning i Basel och fick i hård internationell konkurrens ett åtråvärt hedersomnämnande, i praktiken ett andrapris. Det var en viktig signal att vi kanske var på rätt väg. Själv inbjöds jag att berätta om ekomuseet i både Frankrike och England.

Peter Larsson anställdes 1991 som museichef. Ekomuseet fick efter en provisorisk början fast kansli i Fagersta, senare i Smedjebacken.

Kontaktorganet Ekobladet började utges till alla intresserade. En guideutbildning kom igång och de första "ekoguiderna» examinerades. Man arbetade vidare på att förankra ekomuseet hos kommunledningar och turistväsende.

Vintern 1992-93 reste vid två tillfällen en grupp från Ekomuseum Bergslagen till Frankrike, inbjuden av "ursprungsekomuseet" Le Creusot. Avsikten var att hjälpa Le Creusot att komma vidare i sin verksamhet. Sommaren därpå kom en stor delegation från Le Creusot till Bergslagen. Ekomuseum Bergslagen hade en gång funnit inspiration i Frankrike - nu hade man också fått ge tillbaka. Cirkeln var sluten.

Peter Larsson föreläste om ekomuseet i Frankrike, Italien och i Japan. En stor utbytesutställning med Le Creusot och Ironbridge visades på Galleri Astley. EMYA hade sin prisutdelning på ekomuseet i samverkan med länsstyrelsen i Västerås.

Ekomuseet flyttade sitt kansli till Grenanderska gården i Smedjebacken. Under perioden anställdes Stig Bergman med stöd av statens kulturråd som ansvarig för animering av kulturmiljöer. En grupp skådespelare och konstnärer anställdes på projektbasis. Ekomuseet gav ut en ny guidebok på svenska och engelska samt aktivitetskalendrar. Arbetet att förankra idéerna hos dem som medverkade frivilligt gick vidare. Organisationen för Ekorådet genomgick förändring p.g.a. alltför stor tillströmning på mötena. Nya guideutbildningar genomfördes.

\section{6 - EKOMUSEET BLIR 10 AR}

Jag har ibland undrat hur det blivit om de enkla skisser som för nästan 20 år sedan hade formen av en kulturled kring sjön Väsman hade stannat vid den lösningen. Skisserna blev efter hand till ett ekomuseum som i sin tur gick över en länsgräns. Det som hände var en process, som skulle beröra hundratals människor inom sju kommuner. Och den processen pågår fortfarande. Ekomuseum Bergslagen har blivit ett möte mellan miljöer och människor, mellan tid och rum, mellan svenska och franska idéer. Många har varit engagerade och delaktiga i arbetet, anställda, förtroendemän och frivilliga.

I dag står ekomuseet med ny ledning. Man har beslutat sig för att arbeta intensivt med framtidsfrågorna. Låt oss hoppas att vi om ytterligare tio år kan, som vi gjort nu, blicka tillbaka och säga «drivfjädern är fortfarande processen - ekomuseet är på väg»!

\section{NOT}

Texten är en förkortad och bearbetad version av en föreläsning vid Riksutställningars seminarium From Burgundy to Bergslagen, Stockholm 30 maj 1996. 
ÖRJAN HAMRIN

SUMMARY

The Bergslagen ecomuseum - fiom idea to reality

The paper states that Ekomuseum Bergslagen is not a proper ecomuseum in the original French sense of the word. Initially the project was influenced by the French concept and adopted the term - but in many respects it has grown logically out of a set of existing structures and ways of coping with cultural changes. The author points to the initiatives taken in the 1920s by the author, local heritage enthusiast and popular educator Karl-Erik Forsslund (18721941), who lived in the region and created the famous folk high school at Brunnsvik and later, in 1938, founded at Ludvika, the first open-air museum of industrial history in the world. Another influence came from the industrialist Axel Ax:son Johnson, who at Ängelsberg kept in good repair buildings, furnaces, hammer forges and waterwheels reminders of the early steel industry. The site was eventually included in the World Heritage List. When Erik Hofrén became Provincial Antiquarian and Director of the regional Dalarna Museum in 1967, he soon developed ideas about the decentralisation of museum activities, regarding the local historical sites as a network that should be included in the museum's extramural activities. Thus in 1970 a $60 \mathrm{~km}$ heritage and nature trail, Husbyringen, came into being. It was organised as a museum foundation, serving as an umbrella organisation for several small museums, sites and collections. It set the pattern for the kind of ecomuseum, which should be named 'Scandinavian' as it has its counterparts today in both Denmark and Norway.

When plans for the western part of the region, Västerbergslagen, were drawn up, the author offered several ideas akin to the Husby trail. However the project grew in size and in the end it broke both municipality and county boundaries in order to give a comprehensive picture of the, nationally important early industrial history of Bergslagen. The planning work was done in the 1980s and in
1986 the official opening took place. The characteristics of the new museum, which maintains the "umbrella» style, are that the ecomuseum does not own the objects in it, the responsibility for each site stays with a local association, that cooperation with municipal tourist organisations is important and that the museum activities are linked with the cultural affair authorities as well as with the local heritage movement and voluntary workers.

Örjan Hamrin är forste antikvarie vid Dalarnas museum, Falun.

Adr: Dalarnas museum, Box 22, S-791 21 Falun

Fax $+46-23-28358$ 